\title{
WestVirginiaUniversity
}

THE RESEARCH REPOSITORY @ WVU

Graduate Theses, Dissertations, and Problem Reports

2018

\section{Social Media Cyberbullying: Bystander Behaviors and Spiral of Silence}

Minying Kong

Follow this and additional works at: https://researchrepository.wvu.edu/etd

\section{Recommended Citation}

Kong, Minying, "Social Media Cyberbullying: Bystander Behaviors and Spiral of Silence" (2018). Graduate Theses, Dissertations, and Problem Reports. 7200.

https://researchrepository.wvu.edu/etd/7200

This Thesis is protected by copyright and/or related rights. It has been brought to you by the The Research Repository @ WVU with permission from the rights-holder(s). You are free to use this Thesis in any way that is permitted by the copyright and related rights legislation that applies to your use. For other uses you must obtain permission from the rights-holder(s) directly, unless additional rights are indicated by a Creative Commons license in the record and/ or on the work itself. This Thesis has been accepted for inclusion in WVU Graduate Theses, Dissertations, and Problem Reports collection by an authorized administrator of The Research Repository @ WVU. For more information, please contact researchrepository@mail.wvu.edu. 
Social Media Cyberbullying: Bystander Behaviors and Spiral of Silence

Minying Kong

Thesis submitted to the

Reed College of Media at

West Virginia University

in partial fulfillment of the requirements for the degree of

Master of Science in

Journalism

Steve Urbanski, Ph.D., Chair

Bob Britten, Ph.D.

Lois Raimondo, M.A.

Nick Bowman, Ph.D.

Department of Reed College of Media

Morgantown, West Virginia

2018

Keywords: social media cyberbullying, bystander behaviors, spiral of silence

Copyright 2013 Minying Kong 


\section{ABSTRACT \\ Social Media Cyberbullying: Bystander Behaviors and Spiral of Silence \\ Minying Kong}

Many studies have analyzed the factors that affect bystander behaviors in social media cyberbullying, but few studied the influence of the majority voice. To partially fill this gap, this study applied the spiral of silence theory through an experimental design, manipulating the portion of negative comments and positive comments towards the victim. The purpose of this study was to explore if and how the majority voice has an influence on bystanders' behavior towards the victim in social media cyberbullying. A total of 160 responses and 129 valid responses were collected through an online survey. It was found that there was no relation between bystanders' behavior towards the victim and the majority voice. Also, results showed that bystanders considered the majority voice would not affect their perception or behaviors towards the victim in their general encounter with social media cyberbullying. Factors such as "empathy," "good cause" and "others were being mean" were major reasons of being positive towards the victim, while "lack of decency," "overweight" and "lack of interest" were major reasons of being negative. 


\section{Table of Contents}

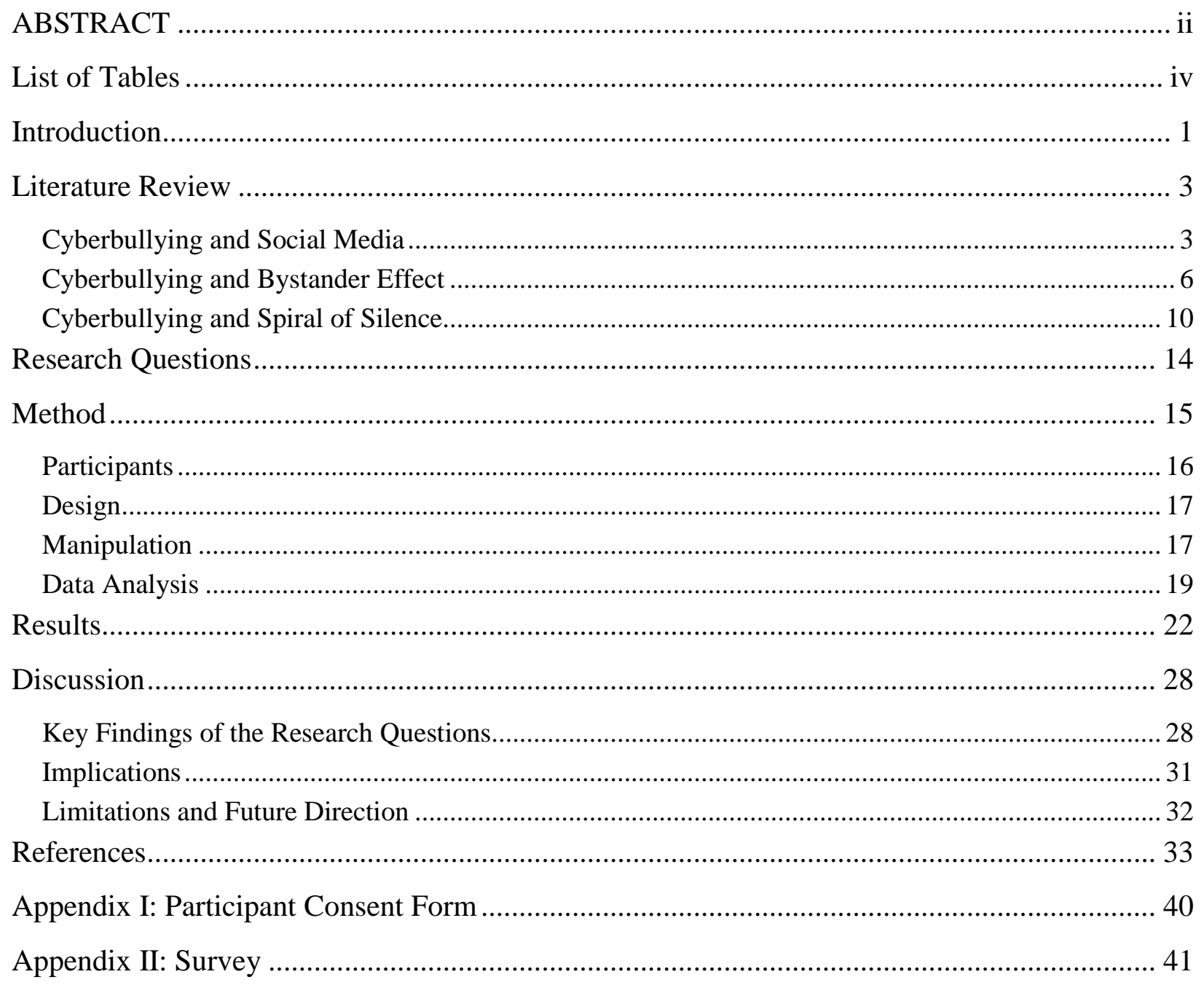




\section{List of Tables}

Table 1. Examples of Each Category of Reasons ............................................................... 21

Table 2. Frequencies of Comments on The Experience of the YouTuber ............................... 23

Table 3. Agreement Differences Between Participants That Did Positive Majority Survey or

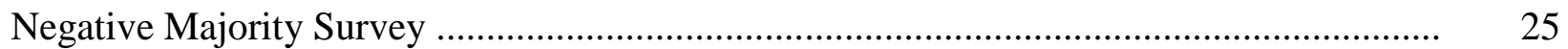

Table 4. Mean Level of Agreement with General Encounter with Social Media Cyberbullying 27

Table 5. Frequencies of Different Comments towards the YouTuber ..................................... 28 


\section{Introduction}

In the last two decades, the Internet, especially in the form of social media, has changed the pattern of human communication. People take advantage of social media to share and collect information on various aspects. Most importantly, social media provide convenient platforms for users to share opinions. People nowadays are consciously and unconsciously spreading their opinions to the world through social media. However, the freedom of speech and convenience of social media has facilitated the widespread phenomenon of cyberbullying.

Cyberbullying is defined as "an aggressive, intentional act carried out by a group or individual, using electronic forms of contact repeatedly and over time against a victim who cannot easily defend him or herself" (Slonje \& Smith, 2012, p. 249). Cyberbullying is skyrocketing. According to Cyberbullying Research Center, approximately $35 \%$ of students aged 11-14 had experienced cyberbullying in 2014; one out of every four teens has experienced cyberbullying, and about one out of every six teens has cyberbullied others in 2015. Many previous studies focused on the perpetrator (the individual who does the bullying) and the victim, analyzing them from different aspects including personality, mentality, education, childhood experience and characteristics of Internet use (Gorzig \& Olafsson, 2013; Ozden \& Icellioglu, 2014; Roberto, Eden, Savage, Rmos-Salazar, \& Deiss, 2014; Doane, Pearson, \& Kelly, 2014). Nevertheless, some studies have probed into the harmful consequences of cyberbullying (Nixon, 2014). However, besides the perpetrator and the victim, there is a group known as "bystanders" of cyberbullying, who are not directly related to cyberbullying but witness the act (Bowers, 
2014). Some studies suggested that bystanders usually do nothing about cyberbullying while other studies considered bystanders contribute to cyberbullying including, positive intervention, nonintervention and passive intervention (Bowers, 2014; Shultz, Heilman \& Hart, 2014). Prior studies analyzed the behaviors of bystanders from the perspectives of diffusion of responsibility, the anonymity of social media, and the relationship between the bystander and the victim (Brody \& Vangelisti, 2016). Based on existing studies, little is known about the effect of the majority on the bystanders, that is, how bystanders make choices or take sides in social media cyberbullying when they know a majority voice exists.

Spiral of silence theory (Noelle-Neumann, 1984) suggested that "a person is less likely to voice an opinion on a topic if one feels that one is in the minority for fear of reprisal or isolation from the majority"(McGregor, Driscoll, \& Mcdowell, 2016, p.226). There is a high tendency for the victims to remain silent, according to previous studies (Patchin \& Hinduja, 2006; Slonje \& Smith, 2008). However, bystanders might also keep quiet when they are confronted with cyberbullying (Barlinska, Szuster, \& Winiewski, 2013; Machackova et al., 2013; Obermaier et al., 2014; Shultz, Heilman, \& Hart, 2014). Therefore, perpetrators are usually the majority voice while the victims are the minority in cyberbullying. The key questions are: How will bystanders take side when they are presented with the majority voice and the minority voice? Is there any possibility that bystander behaviors are impacted by the majority voice?

The purpose of the current study was thus to explore if and how bystanders respond to social media cyberbullying under the influence from the majority's voice (spiral of silence). 
Furthermore, cyberbullying is an emerging field that needs to be explored (Olweus \& Limber, 2017). Thus, another objective of the proposed study was to extend the mass media literature on the effect of spiral of silence on cyberbullying. Most importantly, this study was anticipated to provide information for scholars and practitioners to better understand prevention and intervention efforts in order to effectively reduce cyberbullying and lessen the harm.

\section{Literature Review}

\section{Cyberbullying and Social Media}

Researchers in the past 5-10 years have used various definitions of the concept of cyberbullying (Olweus \&Limber, 2017). In order to prevent future inconsistent findings, Olweus and Limber came up with the "universal definition" of cyberbullying by scanning a large number of previous research publications about cyberbullying. Notably, the relationship between cyberbullying and traditional bullying is widely debated among the researchers. Their universal definition has three components which are (1) "purposeful unwanted negative (aggressive) behavior" (2) "a pattern of repeated behavior" and (3) "an interpersonal relationship characterized by an imbalance of power or strength, favoring the perpetrator(s)." Cyberbullying is considered as "a subcategory or specific form of bullying, in line with other forms such as verbal, physical, and indirect/relational" (Olweus \& Limber). In other words, cyberbullying shares some criteria with traditional bullying. Similarly, Menesini et al. (2012) concluded five definitional criteria for cyberbullying (intentionality, imbalance of power, repetition, anonymity, and public vs. private) and discovered intentionality and imbalance of power were the most 
distinct dimensions around the world. Gross (2016) defined cyberbullying as "using CMC (computer-mediated communication) to communicate and share messages that attack individuals' self-worth." Based on previous research, the major difference between cyberbullying and traditional bullying is that cyberbullying happens in electronic forms (i.e. mobiles, emails, websites, instant message and social media). The overlap in two definitions leads to their overlap in occurrence. According to a prior study, people who have been the victims of school bullying have a high tendency of being the victims in cyberbullying; people who have been the perpetrators also are more likely to be the perpetrators in cyberbullying (Hindujia \& Justin). However, the fluidity of the electronic forms enables the roles of individuals to easily shift from perpetrators, bystanders, and victims (Tokunaga, 2010).

The forms of cyberbullying can be various, including "sending mean or threatening messages, spreading rumors, posting hurtful or threatening messages, hacking person's account to send damaging messages, pretending to be someone else online to hurt another person, taking unflattering pictures of a person and spreading them through cell phones or the Internet, sexting, or circulating sexually suggestive pictures or messages about a person, etc.” (Bullying Statistics). Surveys by the Cyberbullying Research Center show that spreading rumors and posting hurtful or threatening messages are the most common forms. In terms of the degree of harm, previous studies have shown that pictures/videos were the most harmful (Smith, 2008).

It is reported that between $20 \%$ and $40 \%$ of adolescents worldwide have experienced being cyberbullied (Tokunaga, 2010). Statistics from the i-SAFE foundation indicated that more than one in three young people have been victims of online cyberbullying (Bullying Statistics). 
However, cyberbullying is not limited to adolescents with the widespread of social media; people of all ages also are experiencing cyberbullying globally via social media. According to Google Analytics, "over 9.8 million visits in 2016 by people were seeking help with bullying, cyberbullying and online safety." Some scholars considered that given groups of people - the LGBT community and celebrities, for example- are more frequently victims of cyberbullying (Hatzenbuehler \& Keyes, 2013). On a broad scale, cyberbullying can affect all races and genders (Bullying Statistics) and has become an international public health concern (Nixon, 2014).

Many studies have been done on the detrimental impacts of cyberbullying, indicating that it causes mental health and physical health issues for victims, perpetrators and people who are both victims and perpetrators (Nixon, 2014; Hindujia \& Patchin, 2013). Emotionally, they are more likely to experience lowered self-esteem, increased depression, and feelings of powerlessness, anxiety and paranoia (Anderson, Bresnahan, \& Musatics, 2014). Physically, they are more likely to drop out of school, fight, experiment with drugs and carrying a weapon to school (Ericson 2001; Hindujia \& Patchin 2007, 2008, 2009, 2010a; Rigby 2003; Seals \& Young 2003; Slee \& Rigby 1993; Ybarra et al. 2007; Ybarra \& Mitchell 2004). Worse yet, prior research indicates a positive correlation between cyberbullying and suicide (Patchin, 2013).

The reason this current study focuses on social media cyberbullying was that, among all the electronic forms, the extensive use of social media has taken cyberbullying to a new level. The number of social media users worldwide reached 2.46 billion in 2017 , and it is estimated the number will reach 3.02 billion by 2019 (Statista, 2017). According to the Pew Internet Research Center (2011), 9 out of 10 teenagers have witnessed cyberbullying while they were using social 
media. Nobullying.com (2014) revealed that " $55 \%$ of all teens that use social media have witnessed outright bullying online.” Thus, cyberbullying has been a notable issue on social media. Compared with text messages or email, cyberbullying on social media can create larger and more-enduring harm in terms of the time and space. The anonymity of social media adds to the imbalance of power, while the permanent state of the message on social media intensifies the repetition of cyberbullying (Smith et al., 2013). Moreover, the public feature of social media makes victims more vulnerable. To some extent, social media cyberbullying might bring up more stress and harm than cyberbullying via other electronic forms, such as e-mail and textmessaging.

\section{Cyberbullying and Bystander Effect}

Most studies on cyberbullying divide bystanders' behaviors into mainly two types: to intervene or not to intervene (Thornberg et al., 2012). However, in order to better understand bystander's behaviors, some research suggests that bystander behaviors should be further divided into three types: positive intervention (to defend victims and mediate the situation), nonintervention, and passive intervention (to offend victims and join the cyberbullying).

Because cyberbullying is a notable and detrimental issue on social media, bystanders can play an essential role in cyberbullying. The i-SAFE foundation data revealed that more than half of adolescents did not tell their parents when they being cyberbullied (Bullying Statistics). Likewise, one study reported that up to $90 \%$ of adolescents did not tell an adult about their experiences (Juvonen \& Gross). Another study indicated that " $50 \%$ targets did not tell anyone, $35.7 \%$ told a friend, $8.9 \%$ told a parent or guardian, and 5.4\% told someone else" (Slonje \& Smith). In other words, cyberbullying victims are likely to be isolated with their experiences. 
Since victims are usually in a helpless situation, whether bystanders intervene or not and how they intervene, makes a great difference.

However, it is reported that bystanders, who can supportively intervene and create a positive effect, are likely to ignore or even join the cyberbullying (Barlinska, Szuster, \& Winiewski, 2013; Macha ckov a et al., 2013; Obermaier et al., 2014; Shultz, Heilman, \& Hart, 2014). According to the Pew Internet Research Center (2011), "95\% of teens that witnessed bullying on social media report that others, like them, have ignored the behavior." Similarly, data from the Youth Voice Project indicated that about half (51\%) of the youth who had experienced cyberbullying reported that their peers "did nothing" about the situation and "ignored what was going on" (Davis \& Nixion, 2013). Since bystanders might have an impact on social media cyberbullying and many of them have been known to ignore the cyberbullying, it is of great need to explore why people as bystanders tend to ignore social media cyberbullying and are less likely to positively intervene.

Social psychologists Bibb Latané and John Darley (1969) utilized the bystander effect to explain the nonintervention of bystanders after the tragic 1964 murder of Kitty Genovese in New York City. Genovese was stabbed to death outside her apartment. However, bystanders who witnessed the crime did not intervene or call the police (Takooshian, 2014). The bystander effect is mainly due to the perceived diffusion of responsibility and social influence (Latané \&Darley). Diffusion of responsibility indicates that bystanders are more likely to intervene if there are few or no other witnesses. That is to say, each bystander assumes others will help the victim if he or she needs. Social influence suggests that each bystander in a group tend to monitor the behavior 
of those around them to determine how to act. To that end, research conducted by Latané and Darley (1969) suggests that the more bystanders who witness an emergency, the less likely it becomes that any individual will intervene and help.

While results from Latané and Darley were in the face-to- face context, findings from several recent studies in the context of CMC are consistent with the bystander effect as well (Bowers, 2014; Machackova, Dedkova \& Mezulanikova, 2015). In a prior study, where individual and contextual factors (including empathy, social self-efficacy, empathic response to victimization, and relationship to the victim) were controlled, participants were more supportive when they witnessed the cyberbullying alone than with more witnesses (Machackova, Dedkova \& Mezulanikova, 2015).

Previous studies also indicated that many other factors affect whether bystanders will intervene. Thornberg (2007) categorized three common reasons of nonintervention: lack of responsibility, trivialization of the situation, and fear of embarrassment. Shultz, Heilman \& Hart (2014) suggested that although several research studies used a similar definition of cyberbullying (Freis \& Gurung, 2013; Hindujia \& Patchin, 2012,2013; Li, 2010), the general public might have a different understanding of cyberbullying. In other words, it is possible that bystanders do not intervene because they do not identify with or notice the cyberbullying. For instance, it may be difficult to differentiate teasing and cyberbullying (Desmet et al., 2012), and there can be cultural differences in defining cyberbullying.

Mills and Babrow (2003) considered teasing a normal component of growing up into adults. People engage in teasing as a social influence strategy to "shape untoward behavior," which is 
defined as to shape any behavior that is inappropriate and incongruent with social norms (Mills \& Babrow, 2003, p.275). In their study, teasing can force the teased individual to reconsider their behavior without feeling attacked. That is, teasing can bring up positive effects when used appropriately (Bowers, 2014). However, cyberbullying has brought up all negative consequences so far according to existing studies. If bystanders confuse the difference between teasing and cyberbullying, it is less likely for them to intervene.

For the cultural differences, in a study where participants aged 11-17 years from six European countries (Italy, Spain, Germany, Sweden, Estonia and France) were presented with a set of 32 scenarios and asked whether it was cyberbullying or not, French participants more often perceived the scenarios as cyberbullying as compared with those in other countries (Menesini et al., 2012).

Moreover, bystanders' perception and judgment on cyberbullying may rely on the context and the lens, which are influenced by culture, age, sex and social relationships with the involved parties (Thornberg et al., 2012). Bystanders' behaviors are also associated with personality traits, including empathy, extraversion, and self-efficacy (Freis \& Gurung, 2013; Polyhonen, Juvonen, \& Salmivalli, 2010). For instance, researchers conducted a cyberbullying simulation and showed that bystanders with high level of empathy would supportively intervene (defend the victim or mediate the situation) (Shultz, Heilman \& Hart, 2014).

Previous studies utilized bystander effect and other factors to explain bystanders' nonintervention to cyberbullying. However, how will bystanders take sides when they are presented with the majority voice and the minority voice? Is there any possibility that bystanders 
are influenced by the majority on social media cyberbullying when they know the majority voice exists? Imagine a social media user witnessing someone being bullied on social media and that the number of the negative and supportive comments to the victim are nearly the same. How likely is it that this user will intervene? And now imagine that the number of the negative comments are much prevalent than positive comments. Compared to the first scenario, would the user now be equally willing to intervene and help?

This study follows and adds to this growing research stream of bystander behaviors and psychology. In order to further explore if and how bystanders decide to behave in social media cyberbullying, this study incorporates the spiral of silence theory into the understanding of the majority's influence on bystanders.

\section{Cyberbullying and Spiral of Silence}

Spiral of silence was originally used to analyze and describe how people and the climate of public opinion affect opinion formation and sharing (Noelle-Neumann, 1984). The spiral of silence refers to "the increasing pressure people feel to conceal their views when they think they are in the minority." In this theory, Noelle-Neumann suggested that people with opinions perceived as inferior or unpopular (i.e., the minority) are less likely to voice their opinion and the main reason is the fear of isolation and rejection. In other words, those people care about how others see them and fear being cut off from their social circles. For example, Noelle-Neumann conducted an experiment and found that when nonsmokers were nearby, many smokers were less willing to openly support smokers' rights. She also emphasized that the longer people remain 
silent, the more they spiral into a state of total silence, in which they will never voice their opinion.

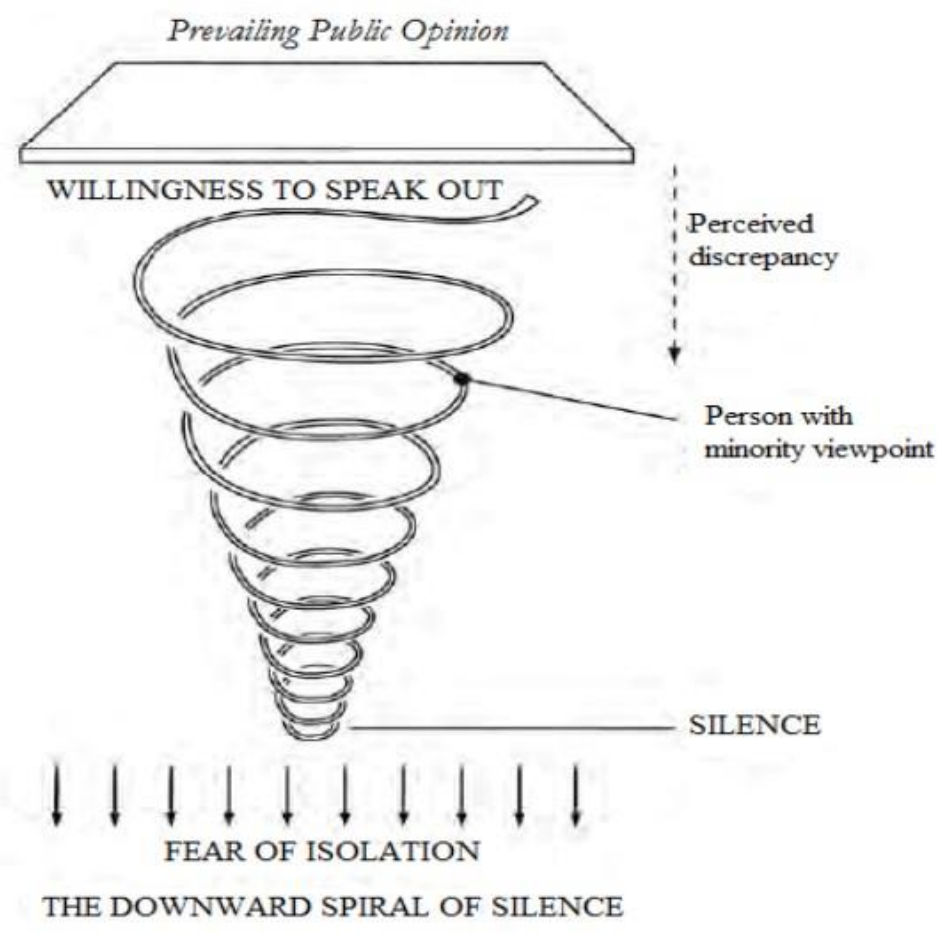

(Scientific Journal of Research, Achyut)

Spiral of silence was widely used in analyzing the public opinion on political issues such as the unexpected outcome of the 2016 U.S. presidential election and the United Kingdom's Brexit vote (Roulet, 2016). Due to the widespread prediction of a Hillary Clinton victory by the media and commentators, the partisans of Donald Trump perceived themselves as the minority and rarely expressed themselves on social media, compared with the supporters of Clinton. In fact, a large number of people who feared of being judged on social media by supporting Trump voted for Trump, while partisans of Clinton believed they were the majority and thought they had already won and thus might be less likely to go vote (Roulet, 2016). Similarly, in the case of the 2016 Brexit referendum, experts and scholars were clearly against the United Kingdom leaving 
the European Union (EU) due to the economic consequences. Although the polls showed a probable victory for the Remain side before the vote day, British people shocked the world by voting for Brexit. Moreover, the Pew Center conducted a survey of 1801 adults on Edward Snowden's 2013 revelations of the U.S. government surveillance of Americans' phone and email records (2014). The results showed that Facebook and Twitter users were less likely to share their views on the Snowden-NSA issue if they did not feel that their friends or followers agreed with their opinions (2014).

Spiral of silence also has become more relevant in terms of online communities as social media cyberbullying become a notable issue. Social media not only creates online communities that allow people express opinions, it also lets users interact with those opinions. Social media users can see what other users agree or disagree with in the comment sections and by the "like," "retweet," "heart," "angry" and other buttons on different social media platforms. In other words, users are able to easily differentiate other users who have different voices. In this case, the effect of spiral of silence can manifest itself in both victims and bystanders of cyberbullying.

According to a prior study, victims of social media cyberbullying are afraid to speak up for fear of being further isolated and shamed, by which they continue fall deeper into the spiral as they feel more isolation and rejection from their peers (Rodgers, 2014). Online bystanders who want to defend the victim might consider themselves as the minority compared with the hostile majority and thus fear to speak up due to the possible reprisal or isolation. They might fear of becoming victims if they try to supportively intervene and defend the primary victim. For example, people might know what is unethical; however, when he or she sees a large number of 
people are leaving hostile or aggressive comments under a celebrity's social media page because of his or her misbehavior in the public, they might be less likely to defend the celebrity but more likely to do nothing or join the cyberbullying.

In January 2016, 16-year-old singer Zhou Ziyu (Tzuyu) introduced herself as Taiwanese while holding the Republic of China (ROC) flag on the South Korean variety show "My Little Television" (Jackson, 2016). Although Zhou held the flag for only three seconds during the show, social media users from Mainland China were in outrage, accusing Zhou making money from China but holding a pro-independence stance. The majority Mainland Chinese turned the divergent political views into malicious personal attacks and an overall boycott of her music. People from Mainland China, who mainly hold the opinion that Taiwan is part of the territory of China, considered Zhou should identify herself as a Chinese and should not wave a flag of ROC on the South Korean show. However, some people from Taiwan, who are pro-independence, maintained support for Zhou. As China has a large population of over 1.3 billion, the social media users from Mainland China are much greater than that from Taiwan. Thus, the opinion of Mainland China users became the majority, i.e., strength in numbers. Under the spiral of silence, the strong become stronger while the weak become weaker. With numerous malicious attack on Facebook and Weibo (a Chinese social media), Zhou finally apologized through a videotape under the public pressure on January 15, 2016. Although some Chinese fans of Zhou showed their support for her, China's tightly censored media dismissed their comments as they continue to rage on Zhou, deeming her apology insincere (Buckley \& Ramzy, 2016). Thus, some who supported Zhou chose to remain silent or they might be attacked by the majority of people from 
Mainland China. Ho, the Hong Kong singer who supported Zhou, forwarded Zhou's apology video on Facebook and showed her sympathy for Zhou. Without surprise, she received thousands of malicious attack on her Facebook and was boycotted in Mainland China (China Daily, 2016). In China, social cyberbullying can be related to the government. In this case, if people knew the consequence of defending the victim and would get in trouble with the government, they would not intervene and comment. So the culture differences would affect the influence of the majority voice in a way.

The bystander effect indicated that bystanders' nonintervention was due to the diffusion of the responsibility and considering that others would assist the victims. Unlike previous studies, the objective of the proposed study was to explore whether bystanders' behaviors were influenced by the majority voice in social media cyberbullying by applying the spiral of silence theory.

\section{Research Questions}

Previous studies have shown the magnitude of spiral of silence in political incidents such as the 2016 U.S. Presidential Election and The Taiwan Flag Incident (Roulet, 2016; Jackson, 2016); people who considered themselves as the minority group were less likely to express their actual views. Moreover, evidence from prior research indicated that victims in cyberbullying tend to perceive themselves as the minority and are less likely to voice their opinions (Patchin \& Hinduja, 2006; Slonje \& Smith, 2008). While previous studies have provided much insight on 
the elements that feed into cyberbullying, there is a lack of research on bystander behaviors under the influence of the majority voice.

In the spiral of silence theory, the reason people who perceive themselves as the minority are less likely to voice their views is being afraid of isolated due to the difference from the majority. In other words, these people would not express their actual views or they would voice the same opinions as the majority in order to conceal the actual difference with the majority. In the case of social media cyberbullying, little was known about the influence of the majority voice on bystanders. To partially fill this gap, this study aimed to answer the following research questions: RQ1: Are there any significant differences in the bystanders' behaviors towards the victim when presenting with differing majority voices?

RQ2: How likely are bystanders to be influenced by the majority voice towards the victim?

RQ3: What other factors influence bystander's behaviors in social media cyberbullying beside the majority voice?

\section{Method}

The approach to answer the research questions was to conduct an online survey. The survey engaged different proportion of negative and positive responses towards the victim to examine if and how the majority voice impacts the behaviors of bystanders in social media cyberbullying.

Based on the timeline and the amount of data, an online survey was an effective tool for the current study. "Applying the experimental design in survey research allows the combination of 
scientific rigor with the convenience of large and sometimes representative samples" (Lopes, 2017, p. 1). In this study, online survey was used to collect representative samples of collegeaged students with high exposure to social media cyberbullying. Also, the method of online survey can collect a large amount of data from various students across the campus without distance boundaries (Wimmer \& Dominick, 2015).

\section{Participants}

The research studied young college-aged adults. After obtaining IRB approval, participants were recruited from West Virginia University students who were over the age of 18, ranging from 18 to 30. The motivation for recruiting this specific sample were to make use of a convenient student population who are the major group of active social media users (Pew Research Center, 2017) and who may possibly have higher exposure to social media cyberbullying. According to the Pew Research Center, young adults at the age of 18 to 29 have the highest rate of using social media in the recent decade. Moreover, existent research on social media cyberbullying focused on primary school and high school students, so there is a lack of research for college-age-category (Aftab, 2014, para. 8; Bowers, 2014). Participants were selected by sending invitations to their emails that asked to complete a self-administrated online survey. Participants completed the electronic informed consent document after selecting the recruitment email. They were assured that the participation was voluntary and all the responses would be kept confidential and used only for research purposes. They were also informed that they could discontinue the survey at any time if feeling uncomfortable. 
As a thank you for participating, participants had the chance to win one of five $\$ 20$ Amazon gift cards. A separated link for the raffle were embedded at the end of the survey. The study obtained the email addresses of the participants in order to distribute the gift cards. Participants who got the gift cards received the digital code for the gift cards through email.

\section{Design}

The study assessed different conditions by having participants complete one of two versions of an online survey. After completing the informed consent, participants were randomly assigned to one of two survey conditions in which the majority characterized the subject either positively or negatively. Among 129 valid responses, 65 participants finished the positive majority survey (50.4\%) and 64 participants finished the negative majority survey (49.6\%). Given the survey had an odd distribution, a difference of one was essentially considered as an 50/50 distribution.

The study procedure included three steps: (1) participants experienced a social media cyberbullying instance with various comments and left one hypothetical comment as part of the online discussion and another one to explain their response, (2) participants indicated their level of agreement with various statements about the experience of the YouTuber, (3) and participants indicated their level of agreement of various statements about their general encounter with social media cyberbullying. Each item in step (2) and (3) ranged from strong disagreement to strong agreement on a seven-point Likert scale.

\section{Manipulation}

Participants were presented with a real case of a YouTuber named boogie2988 posting a video of him doing the Ice Bucket Challenge, an activity of dumping a bucket of ice and water 
over his head to promote the awareness of the disease amyotrophic lateral sclerosis (The link of the video: https://www.youtube.com/watch?v=141O1Q2eLSQ ). Comments in the survey were mostly the real comments from viewers of the video on YouTube. Usernames were randomly changed in order to protect their anonymity. The only difference between the two surveys was the proportion of positive and negative comments. The positive majority survey presented more positive comments than negative comments (eight out of 10 are positive comments) while the negative majority survey presented more negative comments than positive comments (eight out of 10 are negative comments). The rationale of this was to explore the magnitude of spiral of silence in social media cyberbullying via examining the influence of the majority voice on online bystanders.

\section{Measurement}

The current study used two seven-point scales to examine bystanders' behaviors when exposed to the differing majority voices. The first scale was revised from a nine-item scale used by Gross (2016) in his disconfirming condition survey to measure the adherence to group norms in social media cyberbullying. The first scale was designed to measure bystander's behavior under different majority voice.

The second scale of the current study included five items was created by the researcher to measure bystanders' general encounter with social media cyberbullying and perceptions on majority voice. 


\section{Data Analysis}

Since the survey contains both open-ended questions and closed-ended questions, qualitative data and quantitative data were collected and analyzed. Qualitative data were analyzed by two independent coders while quantitative data were analyzed with SPSS.

Coding. The coding units were 129 valid answers to the two open-ended questions in the survey. Each answer of these questions was examined and coded by two independent coders. The coding procedures included the identification of the comments towards the victim and reasons for the comments. Prior to the coding procedure, the researcher explained the coding scheme and provided instructions to the other coder.

For the first open-ended question, two independent coders needed to identify whether the comment from the respondent was negative or positive towards the victim. The average word count of this question is eight. 16 participants refused to leave a comment, for example, "no comment" and "I wouldn't leave a comment." The coders independently coded each item by marking numerical value (1= "being positive," $2=$ "being negative," $3=$ "I don't comment"). A comment could only be given one single code within above three codes. In this section, only three comments were coded differently by two coders. They were "Funny," "This guy seems funny!" and "I feel uncomfortable with the photo and some of the comments. For the comments, it's okay to describe real personal feelings, but it's not appropriate for sarcasm and laughing". After discussion, "Funny" and "This guy seems funny" were considered as "being positive (1)" while the later one as "being negative (2)". Cohen's kappa was adopted to calculate intercoder (interrater) reliability, which determined "the degree of agreements between two raters is higher 
than would be expected by chance" (Sun, 2011, p. 146). As a result, the reliability for the comments towards the YouTuber (.93) was tested. Based on Cohen's (1960) suggested interpretation of kappa result (0.21-0.40 as fair, 0.41-0.60 as moderate, 0.61-0.80 as substantial, 0.81-1.00 as near perfect agreement), the result of intercoder reliability of the first open-ended question was near perfect.

The second open-ended question asked the reasons of the way participants commented. Among the 129 effective participants, none had a blank answer. The average word count of these answers is 10 . The coding of this part was done through emergent coding, which means "the resulting category system is constructed based on common factors or themes that emerge from the data themselves" (Wimmer \& Dominick, p168). By line-by-line viewing the data, the researcher took basic notes that mainly focused on capturing common factors among the answers under the first impression. Keywords, for example, "good cause," were written down as a reference to develop the categories. Then the researcher organized and grouped the coded data into categories based on the occurrence frequency of those keywords. At the end, the researcher determined nine common factors addressing why participants commented the way they did in the survey. The results and examples of them are detailed below (see Table 1).

After developing the categories of the reasons, two coders independently coded the answers of the second open-ended question. A comment could be given only one single code. And both coders only were allowed to choose from those nine codes developed by the researcher. Cohen's kappa was run to determine the agreement rate between two coders' judgment on the reason of 
the comments from the participants. Result showed that there was near perfect agreement between two coders, $\mathrm{k}=.963(95 \% \mathrm{CI}), p<.001$.

Also, according to the frequency of various items, they clustered into nine major categories: empathy ( $n=30)$, good cause $(n=33)$, others were being mean $(n=22)$, respect $(n=6)$, overweight $(n=10)$, lack of decency $(n=9)$, lack of interest $(n=10)$, usually don't comment $(n=8)$, meaningless $(n=1)$.

Table 1. Examples of Each Category of Reasons

\section{Examples}

Empathy

"I try to put myself in his position and reply with things I would like to receive"; "Because no one should be judged by their appearance"

Good cause

"It's a good job that he is promoting a good cause"; "Despite his appearance he's contributing to a good cause"

Other were being mean

"There were people judging him for his appearance"; "To defend him against the bullying"

\begin{tabular}{ll} 
Respect & "Show respect", "I respected his accomplishment" \\
\hline Overweight & "Being fat is a kind of sickness"; "Fat people make me laugh"; \\
\hline Lack of decency & "I usually don't see overweight people shirtless"; "I am not the on \\
& like looking at a man without a shirt" \\
\hline Lack of interest & "None of my business"; "Not interested" \\
\hline Usually don't comment & "I usually don't comment or feed into comment fights"; "I don't \\
& comment on social media"
\end{tabular}




\section{Results}

\section{Overview}

The survey of this study included a total of 160 participants. However, 29 participants did not complete the survey; 2 participants did not answer the questions that allowed the researcher to identify their survey condition. Thus, this study generated a total of 129 valid responses, with females $(79 \%)$, males $(23 \%)$, other $(2 \%)$ and preferred not to mention their gender $(1 \%)$. The average age of the sample is 21.75 , with $\mathrm{SD}=3.95$. Participants described themselves as: $69 \%$ currently attending college $(n=89), 11.6 \%$ bachelor's degree earned $(n=15), 19.4 \%$ master's degree or higher $(n=25)$. The ethnicity participants reported was: $62.8 \%$ White or European American $(n=81), 17.1 \%$ Asian or Asian American $(n=22), 6.2 \%$ Black or African American (n $=8), 6.2 \%$ Hispanic $(n=8)$ and $7.8 \%$ other ethnicity $(n=10)$.

The average level of concern about social media cyberbullying is 3.89 (SD =.94) in fivepoints Likert scale. None of the participants had viewed the picture or video before.

Research Question 1. The first research question examined whether there are any significant differences in bystanders' behaviors towards the victim when presenting with two differing majority voices. The open-ended responses that participants entered as the comments on the experience of the YouTuber were examined and coded. Frequencies were used to answer this research question (See Table 2). Among 65 participants who finished the positive majority 
survey, $10.7 \%(\mathrm{n}=7)$ were "being negative", $80 \%(\mathrm{n}=52)$ were "being positive" and $9.2 \%(\mathrm{n}=6)$

expressed that they had no comment for the YouTuber. Among 64 participants who finished the negative majority survey, 17.2\% (n=11) were "being negative", $66.2 \%(n=43)$ were "being

positive" and 15.6\% $(\mathrm{n}=10)$ expressed that they had no comment for the YouTuber. A chi-square test of independence was conducted to examine the relation between bystanders' comments towards the victim and the majority voice. Results suggested that there was no significant difference in attitudes towards the YouTuber in two surveys $\left(\mathrm{X}^{2}=1.52, \mathrm{~N}=113, \mathrm{p}=.217\right)$. In other words, it suggested that the majority voice and minority voice have no significant effect on bystanders' behaviors towards the victim in this experimental study.

From another perspective, it also showed a "positive bias," which suggested that the participants in the study were simply more likely to make positive codes no matter how positive or negative the comments on a page are.

Table 2. Frequencies of Comments on The Experience of the YouTuber The Positive Majority Survey The Negative Majority Survey

\begin{tabular}{lcccc}
\hline & $\mathrm{n}$ & $\mathrm{a} \%$ & $\mathrm{n}$ & $\mathrm{b} \%$ \\
\hline Being positive & 52 & 80.0 & 43 & 66.2 \\
\hline Being negative & 7 & 10.7 & 11 & 17.2 \\
\hline No comment & 6 & 9.2 & 10 & 15.6 \\
\hline
\end{tabular}

Note. $\% \mathrm{a}=$ percentage with positive, $\mathrm{n}=65 ; \% \mathrm{~b}=$ percentage with negative, $\mathrm{n}=64$.

To further answer RQ1, $t$-tests were conducted to compare the ten items below (See Table 3). Before conducting the t-test, internal consistency of the scales, which describes how closely 
related a set of items are as a group, was tested by calculating their Cronbach's Alpha. Result showed that the internal consistency of the scale was unacceptable $(\alpha=.416)$ based on the interpretation of Cronbach's Alpha $(0.7<\alpha<0.8$ as acceptable, $0.5<\alpha<0.6$ as poor, $\alpha<0.5$ as unacceptable). The current study added three items to the scales but Alpha showed that these items did not fit as a scale. They were "I would like to share this video or picture to the people I know", "People shouldn't feel like they have to restrict their comments online", and "I could identify that there is a popular/majority opinion group".

Thus, the independent-sample $t$-test was conducted on each item below (See Table 3). Among all these $t$-tests, only three items showed significant difference with the survey condition. The first one was "I could identify that there is a popular/majority opinion group" ( $t=-1.98, p$ $=.05)$, in which the negative majority group $(\mathrm{M}=5.39)$ was higher than the positive group $(\mathrm{M}=$ 4.88). The second one was "I thought the responses of the people in the comment sections were mostly negative towards the YouTuber" ( $\mathrm{t}=-4.535, \mathrm{p}=\sim .001$ ), in which the negative majority group ( $M=5.73)$ was higher than the positive group ( $M=4.46)$. The last one was "The responses of people in the comments section are acceptable" $(\mathrm{t}=3.34, \mathrm{p}=.001)$, in which the positive majority group $(M=3.14)$ was higher than the negative group $(M=2.30)$.

Table 3. Agreement Differences Between Participants That Did Positive Majority Survey or Negative Majority Survey

$\underline{\text { Positive }} \quad \underline{\text { Negative }}$

Statements

M SD $\quad$ M $\quad$ SD




\begin{tabular}{|c|c|c|c|c|c|c|c|}
\hline $\begin{array}{l}\text { I would like to share this video or picture to the } \\
\text { people I know. }\end{array}$ & 3.13 & 1.39 & 2.84 & 1.62 & 1.05 & .294 & 0.19 \\
\hline $\begin{array}{l}\text { I understood the different opinions of the people } \\
\text { in the comments section. }\end{array}$ & 4.54 & 1.55 & 4.14 & 1.77 & 1.36 & .177 & 0.24 \\
\hline $\begin{array}{l}\text { I could identify that there is a popular/majority } \\
\text { opinion group. }\end{array}$ & 4.88 & 1.47 & 5.39 & 1.48 & -1.98 & .050 & 0.34 \\
\hline $\begin{array}{l}\text { I thought the responses of the people in the } \\
\text { comment sections were mostly negative towards the } \\
\text { YouTuber. }\end{array}$ & 4.46 & 1.58 & 5.73 & 1.61 & -4.53 & $\sim .000$ & 0.79 \\
\hline $\begin{array}{l}\text { The responses of people in the comments section } \\
\text { are acceptable. }\end{array}$ & 3.14 & 1.37 & 2.30 & 1.51 & 3.32 & .001 & 0.58 \\
\hline $\begin{array}{l}\text { The responses of people in the comments section } \\
\text { are appropriate. }\end{array}$ & 2.77 & 1.32 & 2.53 & 1.75 & .874 & .384 & 0.15 \\
\hline $\begin{array}{l}\text { The comments in the comment section are similar to } \\
\text { what would be found on social media. }\end{array}$ & 5.77 & 1.51 & 5.86 & 1.24 & -.370 & .712 & 0.07 \\
\hline $\begin{array}{l}\text { People should be allowed to honestly comment } \\
\text { about others. }\end{array}$ & 4.60 & 1.51 & 4.30 & 1.65 & $\begin{array}{c}1.09 \\
0 \\
\end{array}$ & .278 & 0.19 \\
\hline $\begin{array}{l}\text { People shouldn't feel like they have to restrict their } \\
\text { comments online. }\end{array}$ & 3.40 & 1.72 & 3.25 & 1.75 & .491 & .624 & 0.09 \\
\hline $\begin{array}{l}\text { Social media is a place where people can give } \\
\text { honest opinion about the others, even if those } \\
\text { opinions are negative. }\end{array}$ & 3.94 & 1.95 & 3.89 & 1.82 & .144 & .886 & 0.03 \\
\hline
\end{tabular}

Research Question 2. The second research question examined how likely bystanders would be influenced by the majority voice towards the victim. Before answering RQ2, internal consistency of the scales was tested by calculating their Cronbach's Alpha. Results showed that the internal consistency of the scale was unacceptable $(\alpha=.498)$ based on the interpretation of Cronbach's Alpha $(0.7<\alpha<0.8$ as acceptable, $0.5<\alpha<0.6$ as poor, $\alpha<0.5$ as unacceptable).

Thus, five one- sample $t$-tests were run (see table 4 ), as the below items asked participants their level of agreement with the statements ( $1=$ strongly disagree $-7=$ strongly agree $)$ in a sevenpoint Likert scale. Mean score of the statement "In general, I can identify if there is a 
majority/popular opinion group $(\mathrm{M}=5.33, \mathrm{SD}=1.31)$ " was statistically significantly higher than the scale's midpoint $4.0(\mathrm{t}=46.0, \mathrm{p}=\sim .000)$, indicating a general perception of the existence of a majority group in social media cyberbullying. Also, mean score of the statement "In general, the majority/popular opinion group are people who are hostile or negative towards the victim $(\mathrm{M}=4.41, \mathrm{SD}=1.51)$ " was statistically higher than the scale's midpoint $4.0(\mathrm{t}=33.0, \mathrm{p}=\sim .000)$, indicating a general perception that the negative voice is the majority in social media cyberbullying.

However, most participants disagreed with the statements "In general, the majority/popular opinion group affect my perception towards the victim $(\mathrm{M}=3.33, \mathrm{SD}=1.67)$ ", "In general, I will look at most people's standpoint before I leave a comment $(\mathrm{M}=3.86, \mathrm{SD}=1.85)$ " or "In general, the majority/popular opinion group affect my behaviors towards the victim $(\mathrm{M}=2.80, \mathrm{SD}=$ 1.55)" (see Table 4).

The purpose of RQ2 was to examined overall bystanders' probability of being influenced by the majority voice in general encounter in social media cyberbullying. So the mean of these items was compared as one group, instead of separate group (the negative majority or the positive majority).

Table 4. Mean Level of Agreement with General Encounter with Social Media Cyberbullying

\begin{tabular}{lcccc}
\hline \multicolumn{1}{c}{ Statements } & $\mathrm{M}$ & $\mathrm{SD}$ & $t$ & $p$ \\
\hline $\begin{array}{l}\text { In general, I can identify if there is a majority/popular } \\
\text { opinion group. }\end{array}$ & 5.33 & 1.31 & 46.0 & $\sim .000$ \\
\hline $\begin{array}{l}\text { In general, the majority/popular opinion group affect my } \\
\text { perception towards the victim. }\end{array}$ & 3.33 & 1.67 & 23.7 & $\sim .000$ \\
\hline
\end{tabular}


\begin{tabular}{llllll}
\hline In general, I will look at most people's standpoint before & 3.86 & 1.85 & 22.7 & $\sim .000$
\end{tabular} I leave a comment.

$\begin{array}{lllll}\text { In general, the majority/popular opinion group affect my } & 2.80 & 1.55 & 20.4 & \sim .000\end{array}$ behaviors towards the victim.

$\begin{array}{lllll}\text { In general, the majority/popular opinion group are people } & 4.41 & 1.51 & 33.0 & \sim .000\end{array}$ who are hostile or negative towards the victim.

Note. $\mathrm{M}=\mathrm{Mean} . \mathrm{SD}=\mathrm{Standard}$ Deviation. Level of agreement range from 1 (strongly disagree) to 7 (strongly agree).

Research Question 3. The third research question explored other factors that influence bystanders' behaviors in social media cyberbullying. Participants were asked to explain the reasons for how they commented after viewing the experience of the YouTuber. Responses were coded in order to categorize the reasons. As mentioned above, result of Cohen's kappa showed that there was near perfect agreement between two coders in this coding section, $\mathrm{k}=.963(95 \%$ CI), $p<.001$.

Frequencies showed that the most common reason for "being positive towards the YouTuber" was "good cause" $(\mathrm{n}=30, \%=31.5)$, following by the next common reason "empathy" $(\mathrm{n}=33, \%=34.7)$. Another two reasons of "being positive towards the YouTuber" were identified as "others were being mean" $(\mathrm{n}=22, \%=23.1)$ and "respect" $(\mathrm{n}=7, \%=7.3)$. The outstanding reasons of "being negative towards the YouTuber" were "overweight" $(\mathrm{n}=6, \%=31.5)$ and "lack of decency" $(n=9, \%=47.3)$. The major reasons participants indicated they "don't comment" were they "usually don't comment" $(n=7, \%=46.7)$ and "lack of interest" $(n=7, \%=46.7)$.

Table 5. Frequencies of different comments towards the YouTuber

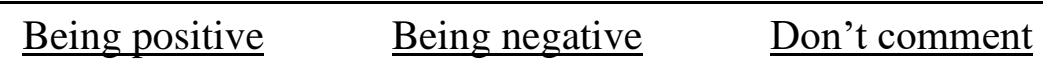




\begin{tabular}{lcccccc} 
Reason & $\mathrm{n}$ & $\mathrm{a} \%$ & $\mathrm{n}$ & $\mathrm{b} \%$ & $\mathrm{n}$ & $\mathrm{c} \%$ \\
\hline Empathy & 30 & 31.5 & 0 & 0 & 0 & 0 \\
\hline Good cause & 33 & 43.7 & 0 & 0 & 0 & 0 \\
\hline Others were being mean & 22 & 23.1 & 0 & 0 & 0 & 0 \\
\hline Respect & 7 & 7.3 & 0 & 0 & 0 & 0 \\
\hline Overweight & 2 & 2.1 & 6 & 31.5 & 1 & 6.7 \\
\hline Lack of decency & 0 & 0 & 9 & 47.3 & 0 & 0 \\
\hline Lack of interest & 0 & 0 & 3 & 15.7 & 7 & 46.7 \\
\hline Usually don't comment & 1 & 1.0 & 0 & 0 & 7 & 46.7 \\
\hline Meaningless & 0 & 0 & 1 & 5.3 & 0 & 0 \\
\hline
\end{tabular}

Note. $\% \mathrm{a}=$ percentage within being positive, $\mathrm{n}=95 ; \% \mathrm{~b}=$ percentage within being negative, $\mathrm{n}=$ $18 ; \% \mathrm{c}=$ percentage within don't comment, $\mathrm{n}=15$.

\section{Discussion}

The current study explored if and how the majority voice has an influence on bystanders' behaviors towards the victim in social media cyberbullying using the spiral of silence. The spiral of silence theory was applied through an experimental design, manipulating the portion of negative comments and positive comments towards the victim. Originally, it was expected that the majority would have an effect on bystanders' behaviors based on previous studies on spiral of silence and cyberbullying. However, the results of this current study suggested differently. The following sections report the key findings of the current study regarding the research questions, implications, limitations and future research direction.

\section{Key Findings of the Research Questions}

The findings of the first research question described the influence of the majority voice on bystanders' behaviors towards the victim. Frequencies showed that participants under different survey conditions had similar percentage of "being positive" and "being negative" towards the 
victim. This study suggested that spiral of silence do not have a significant effect on bystanders' behaviors towards the victim. The findings of the $t$-tests indicated that participants under different survey conditions were aware of the existence of the majority voice, either positive or negative towards the YouTuber. In addition, most participants under both survey conditions considered negative comments toward the YouTuber as unacceptable.

The second research question examined the probability of bystanders being influenced by the majority voice towards the victim in general encounter with social media cyberbullying. Most participants reported that they agreed with the statements that "I can identify if there is a majority/popular opinion group," "the majority/popular opinion group are people who are hostile or negative towards the victim" and "I will look at most people's standpoint before I leave a comment." However, participants disagreed with the statements "the majority/popular opinion group affect my perception towards the victim" or "the majority/popular opinion group affect my behaviors towards the victim." These results suggested that most participants were able to identify the majority voice and considered the majority voice was usually negative towards the victim in their general encounter with social media cyberbullying. Particularly, participants who completed the negative majority survey was seen as more likely to have a majority opinion perception that the positive majority ones. Interestingly, participants would take a look at most people's standpoint before they leave their own comments. However, they perceived that the majority voice or most people's standpoint would not affect their perception or behaviors towards the victim. A possible explanation for these findings is that majority voice was 
nonsignificant while other factors might play bigger roles in bystander's behavior towards the victim.

The findings of the third research question suggested the major factors that influenced participants' perception and behaviors towards the victim. In the study, participants suggested three major reasons of leaving positive comments, which were "empathy", "good cause" and "others were being mean". Similarly, previous researchers also found that bystanders with high level of empathy would supportively intervene (defend the victim or mediate the situation) in cyberbullying (Shultz, Heilman \& Hart, 2014). An example of showing "empathy" in this study was "I try to put myself in his position and reply with things I would like to receive." The second major reason of "being positive" was "good cause", which suggested that participants focused on the action of the YouTuber instead of his appearance; participant tended to defend the good cause. It was worth noting that the third major reason of "being positive towards the victim" was "others were being mean.” In other words, when participants saw others leaving negative comments to the victim, they in fact had an instinct to defend the victim. Also, results showed that none of the participants leave negative comment towards the YouTuber because "others were being mean". These further suggested that participants do not leave negative comments on the victim because of the existent negative comments.

"Lack of decency", "overweight" and "lack of interest" were the top three reasons why participants left negative comments on the victim. A possible explanation of this is that in this study the victim was in big size and shirtless. This suggested that some participants might have 
bias against overweight people. And participants tended to negatively comments on things that are indecent or unpleasant, in this case, a shirtless man.

Participants who wrote down that they usually "don't comment" could be considered as the type of bystanders who would not intervene in a social media cyberbullying. In this study, the major reason of no comment was that these participants did not usually comment on social media. Again, the majority voice did not affect these participants' behavior towards the victim.

Other findings of the current study also provided insight into social media cyberbullying. In this study, the average level of concern of social media cyberbullying is $3.89(\mathrm{SD}=.94)$ in a fivepoint Likert scale. Results suggested that college-aged participants are concerned about social media cyberbullying. Results also showed that none of the participants viewed the picture or video before; only $1.6 \%(\mathrm{n}=2)$ knew the YouTuber before participating in the survey. In other words, it suggested that bystanders' behavior towards the victim do not have a significant difference with their familiarity or relationship with the victim.

\section{Implications}

Under the spiral of silence theory, it was expected that bystanders have a high tendency to be affected by the majority voice on social media cyberbullying and thus choose not to support the victim and join the cyberbullying (Barlin ska, Szuster, \& Winiewski, 2013; Machackov a et al. 2013; Obermaier et al., 2014; Shultz, Heilman, \& Hart, 2014). However, the results of the current study suggested that the majority voice had no significant effect on bystanders' behaviors. Theoretically, it extended the mass media literature on the effect of spiral of silence on social 
media cyberbullying, especially in the college-aged group. Sociologically, considering the mental and physical health impact of social cyberbullying, this study provided a new perspective on bystanders for scholars and practitioners to better understand prevention and intervention efforts in order to effectively reduce social cyberbullying.

In addition, it also shed some light on the news outlet on social media platforms. According to Pew Research Center (2017), "two- thirds of Americans report that they get at least some of their news on social media - with two-in-ten doing so often.” Besides consuming news on social medium platforms like Twitter and Facebook, users are able to view comments from others and leave their own comments. It it possible that users leave comments and cyberbullying someone under the news on social media. Social media cyberbullying might not only cause harms to victims in the news events, but also blurry the facts, cause bias and sway the public opinion. Although this current study showed that participants were not influenced by the negative majority voice in a social media cyberbullying experiment, it is necessary for social media platforms and news outlets to detect the abusive comments and create a healthy environment for news consumption. For example, before users submit the comments, a window from the social media page will pop up and say it might contain abusive words and suggest users not use those words.

\section{Limitations and Future Direction}

Several limitations were revealed in the current study. Frist, the sample in this study was small and female dominant, so it did not generate representative results. According to a prior study, males tend to have more aggressive behaviors in cyberbullying than females (Griezel et 
al., 2012). Thus, in future research, with a larger and gender balanced sample, it might show a significant relationship between the majority voice and bystanders' behavior in social media cyberbullying. Second, the information of the two open-ended questions in the survey did not provide enough data to further analyze factors that affect bystanders' behaviors in social media cyberbullying. Online survey did not provide chance to ask follow-up questions. Future research should consider approaches such as interviews and focus groups. Third, the chosen example of the social media cyberbullying in the experiment might have mislead the participants to present the "nice" side. The description about the YouTuber doing an Ice Bucket Challenge might have led participants to focus on the ALS instead of others' cyberbullying his weight. It might also be possible that participants noticed the negative majority voice but chose to show the "nice" side to the researcher, and thus swayed the results of the study. Further research should pay attention to the selection of the example and setting of the experiment.

\section{References}

Achyut, A. (n.d.). Spiral of Violence: Death of Spiral of Silence and a Farwell to Elizabeth NoelleNeumann. Scientific Journal of Research, 1(2), 34-48.

Anderson, J., Bresahan, M., \& Musatics, C. (2014). Combating weight-based cyberbullying on Facebook with the dissenter effect. Cyberpsychology Behavior and Social Networking. 2014 May;17(5):281-6. Retrieved from doi:10.1089/cyber.2013.0370. 
Bowers, J. M. (2014). Understanding bystander behavior in cyberbullying encounters: an application of bystander apathy theory. Master thesis. Gonzaga University.

Brody, N. \& Vangelisti, A.L. (2016). Bystander Intervention in Cyberbullying, Communication Monographs, 83:1, 94-119. doi:10.1080/03637751.2015.1044256

Bullying Statistics (2017). Cyberbullying Statistics. Retrieved September 29, 2017 from http://www.bullyingstatistics.org/content/cyber-bullying-statistics.html

Bastiaensens, S., Pabian, S., Vandebosch, H., Poels, K., Van Cleemput, K., DeSmet, A., \& De Bourdeaudhuij, I. (2016). From normative influence to social pressure: How relevant others affect whether bystanders join in cyberbullying. Social Development, 25(1), 193-211. doi:10.1111/sode. 12134

Buckley, C \& Ramzy, A. (2016). Singer's Apology for Waving Taiwan Flag Stirs Backlash of Its Own. The New York Times. Retrieved November 27, 2016 from http://www.nytimes.com/2016/01/17/world/asia/taiwan-china-singer-chou-tzu-yu.html?_r=0

Barlinska, J., Szuster, A., \& Winiewski, M. (2013). Cyberbullying among adolescent bystanders: role of the communication medium, form of violence, and

empathy. Journal of Community \& Applied Social Psychology, 23(1), 37e51. http://dx.doi.org/10.1002/casp.2137.

China Daily. (2016). Ho Wan Si Commented on Zhou Ziyu's Apology: Artists from Hong Kong and Taiwan Should Not Be Compromised (in Chinese). Retrieved January 22, 2018 from http://www.chinadaily.com.cn/interface/toutiaonew/1020961/2016-01-16/cd_23114722.html

Connolly, Justin, Pamela Hussey, and Regina Connolly. "Technology-Enabled Bullying and Adolescent Resistance to Report." Interactive Technology and Smart Education 11.2 (2014): 8698. ProQuest. Web. 2 Mar. 2017.

Desmet, A., Bastiaensens, S., Van Cleemput, K., Poels, K., Vandebosch, H., \& De Bourdeaudhuij, I. (2012). Mobilizing bystanders of cyber-bullying: An exploratory study into behavioural determinants of defending the victim. Annual Review of Cybertherapy and Telemedicine, 58-63.

Del Rey, R., Casas, J., \& Ortega, R. (2016). Impact of the conRed program on different cyberbulling roles. Aggressive Behavior, 42(2), 123-135. doi:10.1002/ab.21608

Denyer, S., \& Jing, X. (2016). Watch: Teenage pop star's humiliating apology to China for waving Taiwan flag. The Washington Post. Retrieved November 27, 2016 from 
https://www.washingtonpost.com/news/worldviews/wp/2016/01/16/watch-teenage-popstarshumiliating-apology-to-china-for-waving-taiwan-

flag/?tid=sm_fb\&utm_term=.82af8f $7 \mathrm{~b} 31 \mathrm{f} 9$

Davis, S., \& Nixon, L. C. (2013). Youth Voice Project: Student Insights into Bullying and Peer Mistreatment. Research Press.

Doane, A. N., Pearson, M. R., \& Kelley, M.L. (2014). Predictors of cyberbullying perpetration among college students: An application of the theory or reasoned action. Computers in Human Behavior, 36, 154-162. 〈http:// dx.doi.org/10.1016/j.chb.2014.03.051>

Ericson, N. (2001). Addressing the problem of juvenile bullying OJJDP Fact Sheet, 27. U.S. Department of Justice, Office of Justice Programs, Office of Juvenile Justice and Delinquency Prevention. Washington, DC: U.S. Government Printing Office.

Freis, S. D., \& Gurung, R. A. (2013). A Facebook analysis of helping behavior in online bullying. Psychology of Popular Media Culture, 2, 11-19. http://dx.doi.org/10.1037/a0030239

Gorzig, A., \& Olafsson, K. (2013). What makes a cyberbullying? Unraveling the characteristics of cyberbullies across twenty-five European countries. Journal of Children and the Media, 7,9-27. <http://dx.doi.org/10.1080/17482798.2012.739756>.

Griezel, L., Finger, L., Bodkin-Andrews, G., Craven, R., \&Yeung, A. (2012). Uncovering the structure of and gender and developmental differences in cyber bullying. Journal of Educational Research, 105(6), 442-455.

Goodboy, A.K. and Martin, M.M. (2015), "The personality profile of a cyberbully: Examining the Dark Triad," Computer in Human Behavior, 49, 1-4

Gross, C. M. (2016). The Dangerous Side of Social Media: Manipulating Bystander Aggression and Support to Cyberbullying Victims Through an Application of Side. (Doctoral Dissertation). University of Wisconsin - Milwaukee. Retrieved from http://dc.uwm.edu/etd/1145

Hampton, K.N., Rainie, L., Lu, W., Dwyer, M., Shin, I., \& Purcell, K. (2014). "Social Media and the 'Spiral of Silence.' Pew Research Center, Washington, DC.

http://www.pewinternet.org/2014/08/26/social-media-and-the-spiral-of-silence/

Hinduja, S., \& Patchin, J. W. (2009). Bullying beyond the schoolyard: Preventing and responding to cyberbullying. Thousand Oaks, CA: Sage.

Hinduja, S., \& Patchin, J. W. (2010a). Bullying, cyberbullying, and suicide. Archives of Suicide Research, 14(3), 206-221. doi:10.1080/13811118.2010.494133. 
Hinduja, S., \& Patchin, J. W. (2010b). Cyberbullying: A review of the legal issues facing educators. Preventing School Failure, 55(2), 1-8.

Hinduja, S., \& Patchin, W. (2012). School climate 2.0: Reducing teen technology misuse by reshaping the environment. Thousand Oaks, CA: Sage Publications.

Hinduja, S., \& Patchin, J. (2013). Social influences on cyberbullying behaviors among middle and high school students. Journal of Youth \& Adolescence, 42, 711-722.

http://dx.doi.org/10.1007/s10964-012-9902-4

Hinduja, S. \& Patchin, W. J. (2016). Cyberbullying Research Center. New National Bullying and Cyberbullying Data. Retrieved October 03, 2017 from https://cyberbullying.org/newnationalbullying-cyberbullying-data

Hampton, K., Rainie, L., Lu, W., Dwyer, M., Shin, I., \&Purcell, K. (2014). Social Media and the 'Spiral of Silence'. Retrieved June 15, 2017 from https://www.psychologytoday.com/blog/notjust-bystander/201403/the-1964-kitty-genovesetragedy-what-have-we-learned

Hatzenbuehler, M. L., \& Keyes, K. M. (2013). Inclusive anti-bullying policies and reduced risk of suicide attempts in lesbian and gay youth. Journal of Adolescent Health, 53, S21-S26. Retrieved from https://www.ncbi.nlm.nih.gov/pubmed/23790196

Jackson, D. (2016). 16-year-old K-pop singer waves Taiwan flag, forced to cancel China activities. Shanghaiist. Retrieved from November 27, 2016 from http://shanghaiist.com/2016/01/16/16yearold_k-pop_singer_tzuyu.php

Juvonen, J., \& Gross, E.F. (2008). Extending the school grounds? -Bullying experience in cyberspace. Journal of School Health, 78(9), 496-5050. doi: 10.1111/1469-7610.00629.

Kowalski, R. M., Limber, S. P., Agastson, P. W. (2012). Cyberbullying bullying in the digital age (2nd ed.). Oxford, UK: Blackwell Publishing.

Latané, B. \& Darley, J.M. (1969). Bystander “apathy”. American Scientist, 57(2), 244- 268.

Lopes, R.C. (2017). Experimental Design for Survey Research. Retrieved January 08, 2018 from https://www.europeansurveyresearch.org/conferences/lopes

Li, Q. (2010). Cyberbullying in high school: A study of students' behaviors and beliefs about this new phenomenon. Journal of Aggression, Maltreatment, and Trauma, 19, 372-392. 
http://dx.doi.org/10.1080/10926771003788979

Lenhart, A. (2007). Pew Research Center. Cyberbullying. Retrieved from http://www.pewinternet.org/2007/06/27/cyberbullying/

McGregor, M, A., Driscoll, P, D., \& Mcdowell, W. (2016). Head's Broadcasting in America: A Survey of Electronic Media (10th ed). Routledge.

Machackova, H., Dedkova, L., Sevcikova, A., \& Cerna, A. (2013). Bystanders' support of cyberbullied schoolmates. Journal of Community \& Applied Social Psychology, 23(1), 25e36. http://dx.doi.org/10.1002/casp.2135.

Machackova, H., Dedkova, L., \& Mezulanikova, K. (2015). Brief report: the bystander effect in cyberbullying incidents. $J$ Adolesc, 43(August), 96-99.

Menesini, E., Nocrntini, A., Palladino, B.E., Frisen, A., Berne, S., Ortega-Ruiz, R...Smith, P.K. (2012). Cyberbullying definition among adolescents: A comparison across six European countries. Cyberpsychology, Behavior, and Social Networking, 15(9), 455-463. doi:10.1089/cyber. 2012.0040.

Mills, C. B. \& Babrow, A. S. (2003). Teasing as a means of social influence. Southern Communication Journal, 68, 273-286.

Nixon, C. L. (2014). Current perspectives: the impact of cyberbullying on adolescent health. Adolescent Health, Medicine and Therapeutics, 5, 143-158. http://doi.org/10.2147/AHMT.S36456

Noelle-Neumann, E. (1993). The Spiral of Silence: Public Opinion- Our Social Skin, 2nd ed., University of Chicago Press, Chicago, 1993.

Neuman, W. L. (2011). Social research methods: Qualitative and quantitative approaches. Boston, MA: Allyn and Bacon.

No Bullying. (2014). Cyber Bullying Statistics. Retrieved August 25, 2017 from http://nobullying.com/2014/02/24/cyber-bullying-statistics-2014/

Obermaier, M., Fawzi, N., \& Koch, T. (2014). Bystanding or standing by? How the number of bystanders affects the intention to intervene in cyberbullying?

New Media \& Society. http://dx.doi.org/10.1177/1461444814563519.

Olweus, A., \& Limber P. (2017). Some problem with cyberbullying research. Current Opinion in Psychology. Retrieved from doi: 10.1016/j.copsyc.2017.04.012 
Ozden,M.S., \& Icellioglu, S. (2014). The perception of cyberbullying and cybervictimization by university students in terms of their personality factors. Procedia-Social and Behavioral Sciences, 116, 4379-4383. <http://dx.doi.org/10.1016/j.sbspro.2014.01951〉.

Patchin, J.W., \& Hinduja, S. (2006). Bullies move beyond the schoolyard: A preliminary look at cyberbullying. Youth Violence and Juvenile Justice,4, 148-169. doi: 10. $1177 / 1541204006286288$.

Polyhonen, V., Juvonen, J., \& Salmivalli, C. (2010). What does it take to stand up for the victim of bullying? Merrill- Palmer Quarterly, 56, 142-163.

Pöyhönen, V., Juvonen, J., Salmivalli, Cllllllk. (2012). Standing up for the victim, siding with the bully or standing by? Bystander responses in bullying situations. Social Development, 21(4), 722-741. Doi:10.1111/j.1467-9507. 2012. 00662.x

Pew Research Center. (2017). Social Media Face Sheet. Retrieved January 12, 2017 from http://www.pewinternet.org/fact-sheet/social-media/

Rigby, K. (2003). Consequences of bullying in schools. Canadian Journal of Psychiatry, 48, 583590.

Roberto, A.J., Eden., Savage, M. W., Ramos-Salazar, L., \& Deiss, D. M. (2014). Prevalence and predictors of cyberbullying perpetration by high school seniors. Communication Quarterly, 62,97-114. <http://dx.doi.org/10.1080/01463373/2013/860906>/

Rubin, R., B., Rubin, A. M., Haridakis, P.M., \& Piele, L. J. (2012). Communication research: Strategies and sources (7th ed.). Boston: Wadsworth/Cengage Learning.

Roulet, T. (2016). The Telegraph. Pious progressives have created a spiral of silence which could yet conceal a Donald Trump victory. Retrieved December 23, 2017 from http://www.telegraph.co.uk/news/2016/11/03/pious-progressives-have-created-a-spiral-ofsilencewhich-could/

Rodgers, H. (2014). The Spiral of Bullying. The University of North Carolina Wilmington. https://imcclass.com/2014/10/21/the-spiral-of-bullying/

Slonje, R. \& Smith, P. K. (2008), Cyberbullying: Another main type of bullying? Scandinavian Journal of Psychology, 49, 147-154. 
Shultz, E., Heilman, R., \& Hart, K. J. (2014). Cyber-bullying: An exploration of bystander behavior and motivation. Cyberpsychology: Journal of Psychosocial Research on Cyberspace, 8(4), article 1. doi: 10.5817/CP2014-4-3

"STOMP Out Bullying: The issue of bullying." Nov 2014. Cyberbullying statistics. Retrieved from STOMP out bullying website: http://www.stompoutbullying.org/index.php/informationandresources/about- bullying-and-cyberbullying/issue-bullying/

Statista. Number of social media users world wide from 2010 to 2021 (in billions). Retrieved October 11, 2017 from https://www.statista.com/statistics/278414/number-of-worldwidesocialnetwork-users/

Seals, D., \& Young, J. (2003). Bullying and victimization: Prevalence and relationship to gender, grade level, ethnicity, self-esteem and depression. Adolescence, 38, 735-747.

Slee, P. T., \& Rigby, K. (1993). The relationship of Eysenck's personality factors and self esteem to bully/victim behavior in Australian school boys. Personality and Individual Differences, 14, 371-373.

Sun, S. (2011). Meta-analysis of cohen's kappa. Health Services and Outcomes Research Methodology, 11(3-4), 145-163. doi:10.1007/s10742-011-0077-3

Thornberg, R., Tenenbaum, L., Varjas, J., Meyers, K., Jungert, T., \& Vanegas, G. (2012). Bystander motivation in bullying incidents: To intervene or not to intervene. Western Journal of Emergency Medicine, 13, 247-252.

Thornberg, R., (2007). A classmate in distress: schoolchildren as bystanders and their reasons for how they act. Social Psychology of Education, 10, 5-28.

The guardian, Under the umbrellas: what do Hong Kong's protesters want from China? 2014-09-24 Retrieved from https://www.theguardian.com/world/2014/sep/29/hong-kong-democracyprotestschina-umbrellas-police

Thurlow, C., Lengle, L., Tomic, A. (2004). Computer mediated communication: Social interaction and the internet. Los Angeles, CA: Sage Publications.

Takooshian, H (2014). The 1964 Kitty Genovese Tragedy: What Have We Learned? Retrieved October 15, 2017 from https://www.psychologytoday.com/blog/not-just-bystander/201403/the1964-kitty-genovese-tragedy-what-have-we-learned

Tokunaga, R.S. (2010). Following you home from school: A critical review and synthesis of research on cyberbullying victimization. Computers in Human Behavior, 26, 227-287. 
Wimmer, D., \& Dominick, R. (2015). Mass Media Research: An Introduction, Tenth Edition. Boston, MA: Michael Rosenberg.

Ybarra, M. L., \& Mitchell, J. K. (2004). Online aggressor/targets, aggressors and targets: A comparison of associated youth characteristics. Journal of Child Psychology and Psychiatry, 45, 1308-1316. doi:10.1111/j.1469-7610.2004.00328. x.

Ybarra, M. L., \& Mitchell, K. J. (2007). How risky are social networking sites? A comparison of places online where youth sexual solicitation and harassment occurs. Pediatrics, 121, e350-e357

Ybarra, M. L., Diener-West, M., \& Leaf, P. J. (2007). Examining the overlap in internet harassment and school bullying: Implications for school intervention. Journal of Adolescent Health, 41, S42-S50. doi: 10.1016/j.jadohealth.2007.09.004.

\section{Appendix I: Participant Consent Form}

Dear WVU Student:

You are being asked to participate in an anonymous study conducted by Minying Kong, a Master's student in the Reed College of Media at West Virginia University. This research examines your overall social media use and encounter with cyberbullying on social media sites. You must be 18 years or older to participate in this study and currently be a WVU student. This questionnaire will take less than 10 minutes to complete. 
Participation in this study is voluntary. You may skip certain questions if you want. There are no known risks associated with participation in this study. Completing and returning this online questionnaire indicates that you have given informed consent to participate in this study.

If you would like more information about this research project, feel free to contact the researcher, Minying Kong at mikong@ mix.wvu.edu. This study has been acknowledged by West Virginia University's Institutional Review Board, and is on file as Protocol \#1711868230

For the purpose of this study, cyberbullying is an aggressive, intentional act carried out by a group or individual, using electronic forms of contact against a victim. Before proceeding on with the survey, please indicate your level of concern in social media cyberbullying in general. Not at all concerned

Not very concerned

Not sure

Somewhat concerned

Very concerned

\section{Appendix II: Survey}

\section{Survey Version 1}

\section{Part I}

A YouTuber named boogie2988, who owns 4.3 million subscribers, posted a video about his Ice Bucket Challenge on YouTube in 2014. Below is a screenshot from his video and comments from different viewers. 


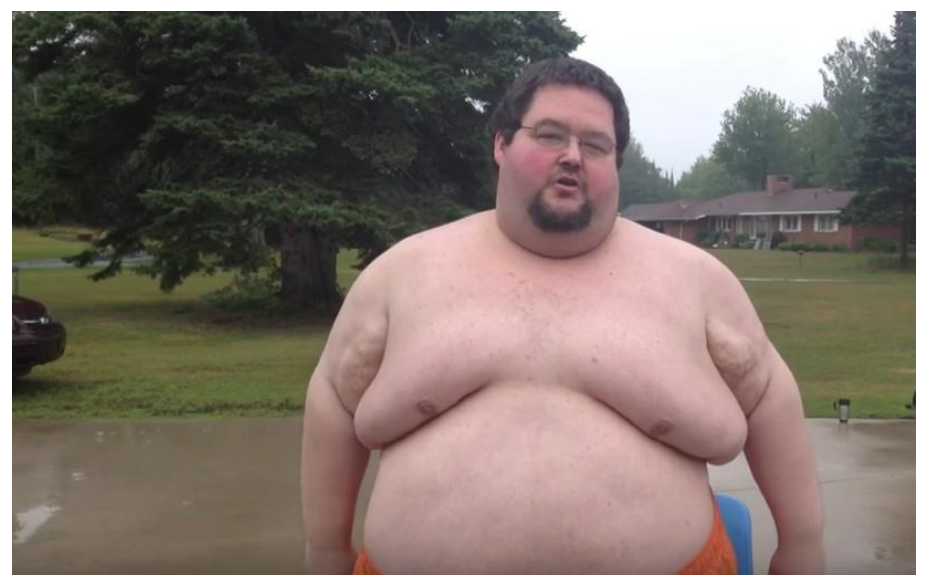

\section{Wow123}

That guy is the coolest.

\section{Thecooljay}

I'm only starting to watch him and he is already one of the best YouTubers.

\section{dumbgamer888}

Does he have diabetes? If he does not, I am surprised.

\section{thelonelygoomba}

Wow these comments are pretty terrible.

\section{John92}

Why there are so many haters?

GR66

I just can't stop laughing. He looks like a big piece of meat.

timemachinell

If anyone said mean things ignore it.

\section{$\Omega$ gamer4life}

To all your haters, show this guy some respect.

\section{Azthetics}

If he likes being like that and enjoys his lifestyle, why do you have to insult him.

fazee

Keep up the awesome videos and forget the haters.

1. Considering the original message and the comments, please write down your comment as part of the discussion here:

2. Why did you react to this picture the way you did? 
3. Considering the comment you entered, do you think it is:

a. Positive towards the YouTuber

b. Negative towards the YouTuber

c. Other (please specify):

4. Did you see this video/picture before?

a. Yes

b. No

5. Do you know this person before?

a. Yes

b. No

\section{Part II}

Consider the previous message about the YouTuber and the comments of various people. Indicate your level of agreement in the following statements (1-7scales from strongly disagree to strongly agree):

1. People should be allowed to honestly comment about others.

2. I would like to share this video or picture to the people I know.

3. The comments in the comment section are similar to what would be found on social media.

4. I understood the different opinions of the people in the comments section.

5. People shouldn't feel like they have to restrict their comments online.

6. Social media is a place where people can give honest opinion about the others, even if those opinions are negative.

7. I thought the responses of the people in the comment sections were mostly negative/hostile towards the YouTuber.

8. I could identify that there is a popular/majority opinion group.

9. The responses of people in the comments section are acceptable.

10. The responses of people in the comments section are appropriate.

\section{Part III}

Consider your general encounter with social media cyberbullying. Indicate your level of agreement in the following statements (1-7scales from strongly disagree to strongly agree):

1. In general, I can identify if there is a majority/popular opinion group.

2. In general, the majority/popular opinion group affect my perception towards the victim.

3. In general, I will look at most people's standpoint before I leave a comment.

4. In general, the majority/popular opinion group affect my behaviors towards the victim.

5. In general, the majority/popular opinion group are people who are hostile or negative towards the victim. 
Please indicate the gender identity that you most identify with. a.

Male

b. Female

c. Prefer not to say

d. Other (please specify)

Please indicate your age:

Please indicate your ethnicity a.

Black/African American

b. Asian/Asian American

c. White-non-Hispanic/European American

d. Hispanic/Latino/Latina

e. Native American/Alaskan Native

f. Hawaiian/Pacific Islander

g. Biracial/Multiracial

h. Other ethnicity (please specify):

Which best describes your highest education level? a.

Currently attending college

b. Bachelor's degree earned

c. Master's degree or higher

Please indicate your major

End of the Survey

To enter into a raffle to win one of five \$20 gift card, please leave your email address in the bank. A digital code for a gift card will be sent you after the data collection.

\section{Survey Version $2 \quad$ Part I}

A YouTuber named boogie2988, who owns 4.3 million subscribers, posted a video about his Ice Bucket Challenge on YouTube in 2014. Below is a screenshot from his video and comments from different viewers. 


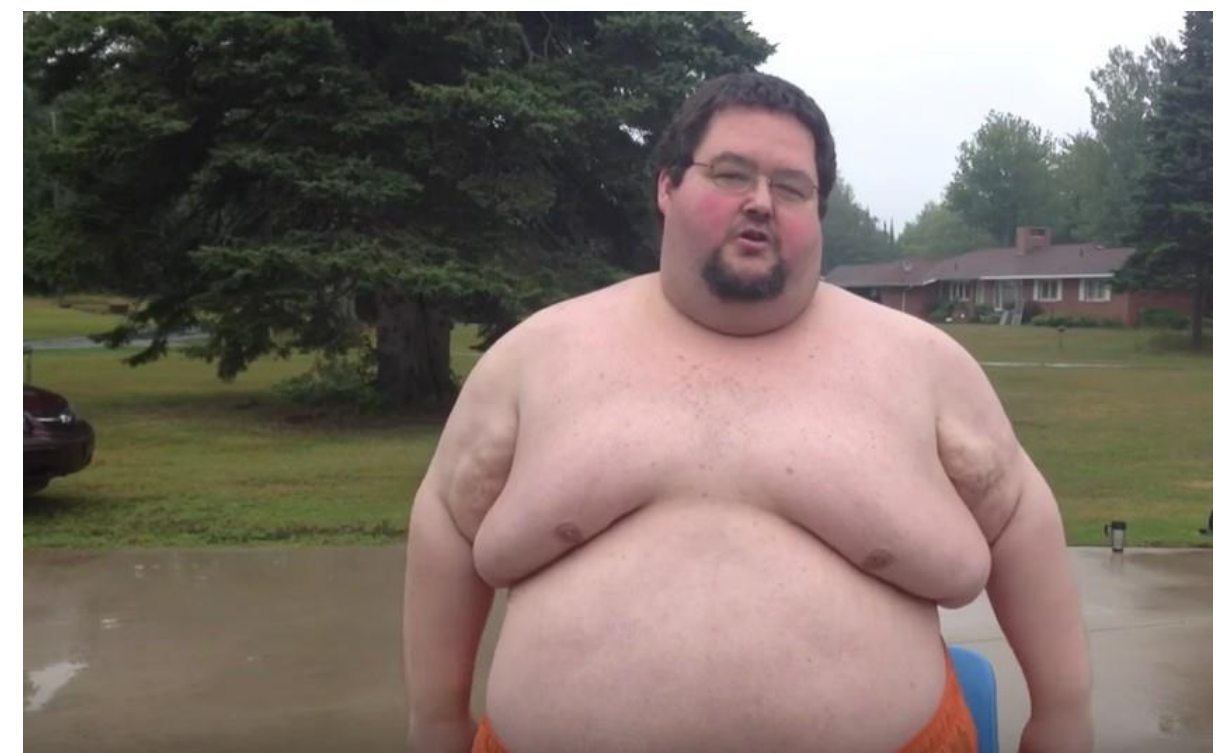

\section{Wow123}

Does he have diabetes? If he does not, I am surprised.

\section{Thecooljay}

I am laughing way too hard at this.

dumbgamer888

My grandma died of ALS. Thank you so much and god bless you.

\section{thelonelygoomba}

It's funny because he is fat.

\section{John92}

I reported this for sexual content lol.

\section{GR66}

You are a very good man and I hope you become more famous.

timemachinell

I just can't stop laughing. He looks like a big piece of meat.

gamer4life

This is sick. I need to wash my eyes.

\section{Azthetics}

Can you imagine that? He looks like a huge piece of meat.

\section{fazee}

$\mathrm{He}$ is so fat that he has no belly button.

1. Considering the original message and the comments, please write down your comment as part of the discussion here: 
2. Why did you react to this picture the way you did?

3. Considering the comment you entered, do you think it is:

a. Positive towards the YouTuber

b. Negative towards the YouTuber

c. Other (please specify):

4. Did you see this video/picture before?

a. Yes

b. No

5. Do you know this person before?

a. Yes

b. No

\section{Part II}

Consider the previous message about the YouTuber and the comments of various people. Indicate your level of agreement in the following statements (1-7scales from strongly disagree to strongly agree):

11. People should be allowed to honestly comment about others.

12. I would like to share this video or picture to the people I know.

13. The comments in the comment section are similar to what would be found on social media.

14. I understood the different opinions of the people in the comments section.

15. People shouldn't feel like they have to restrict their comments online.

16. Social media is a place where people can give honest opinion about the others, even if those opinions are negative.

17. I thought the responses of the people in the comment sections were mostly negative/hostile towards the YouTuber.

18. I could identify that there is a popular/majority opinion group.

19. The responses of people in the comments section are acceptable.

20. The responses of people in the comments section are appropriate.

\section{Part III}

Consider your general encounter with social media cyberbullying. Indicate your level of agreement in the following statements (1-7scales from strongly disagree to strongly agree):

6. In general, I can identify if there is a majority/popular opinion group.

7. In general, the majority/popular opinion group affect my perception towards the victim. 
8. In general, I will look at most people's standpoint before I leave a comment.

9. In general, the majority/popular opinion group affect my behaviors towards the victim.

10. In general, the majority/popular opinion group are people who are hostile or negative towards the victim.

Please indicate the gender identity that you most identify with. a.

Male

b. Female

c. Prefer not to say

d. Other (please specify)

Please indicate your age:

Please indicate your ethnicity a.

Black/African American

b. Asian/Asian American

c. White-non-Hispanic/European American

d. Hispanic/Latino/Latina

e. Native American/Alaskan Native

f. Hawaiian/Pacific Islander

g. Biracial/Multiracial

h. Other ethnicity (please specify):

Which best describes your highest education level? a.

Currently attending college

b. Bachelor's degree earned

c. Master's degree or higher

Please indicate your major

End of the Survey

To enter into a raffle to win one of five $\$ 20$ gift card, please leave your email address in the bank. A digital code for a gift card will be sent you after the data collection. 